\title{
Integrated and mutated forms of Merkel cell polyomavirus in non-small cell lung cancer
}

\author{
Y Hashida ${ }^{1}$, M Imajoh ${ }^{1}$ and M Daibata*,1 \\ ${ }^{1}$ Department of Microbiology and Infection, Kochi Medical School, Kochi University, Nankoku, Kochi 783-8505, Japan
}

Sir,

We appreciate the insightful comments provided by Shuda et al (2013) regarding our recent report 'Detection of Merkel cell polyomavirus with a tumour-specific signature in non-small cell lung cancer' (Hashida et al, 2013).

According to GenBank data, two amino-acid sequences of the non-tumour-derived Merkel cell polyomavirus (MCPyV) strain Appendix206 (GenBank accession numbers JN038578 and JN038579) are deposited under the same title 'Merkel cell polyomavirus isolate Appendix206 large $\mathrm{T}$ antigen gene, partial cds; and small $\mathrm{T}$ antigen gene, complete cds'. In our study (Hashida et al, 2013), we compared the sequences of Appendix206 (JN038578) with the sequences of viral strains isolated from our four $\mathrm{MCPyV}$-positive non-small cell lung cancers (NSCLCs) (SCC15, AC35, AC39 and AC43). As Shuda et al (2013) noted, the two sequences deposited in GenBank with the same descriptions of 'definition', 'source of organism' and 'features' are confusing and indistinguishable.

Our MCPyV strains had the wild-type retinoblastoma tumoursuppressor protein-binding motif. The more important results in our paper are the detection of integrated and large $T(L T)$ gene mutated forms of $\mathrm{MCPyV}$ in one squamous cell carcinoma (SCC15) and one adenocarcinoma (AC43). The tumour AC43 possessed both an integrated MCPyV and frameshift mutations that truncate the $L T$ gene to eliminate its helicase activity. The tumour SCC15 appears to have wild-type MCPyV, as the fulllength $L T$ gene sequence was determined by direct sequencing of polymerase chain reaction products, as shown in Figure 4 in our previous report (Hashida et al, 2013). However, we demonstrated that the AC43 tumour also carried integrated virus with the virus-host junction located in the $L T$ gene at nucleotide position 2738, interrupting the helicase domain (nucleotide positions 19473017). These findings suggest the coexistence in the tumour of an integrated/truncated form and an episomal form of MCPyV. This phenomenon was also reported in MCPyV-positive Merkel cell carcinoma (Laude et al, 2010; Martel-Jantin et al, 2012).

Thus, we found two cases of NSCLC infected with MCPyV possessing a tumour-specific feature, which to our knowledge has not been reported in any specific malignancy other than Merkel cell carcinoma and chronic lymphocytic leukaemia. As Shuda et al (2013) commented, a follow-up study of these MCPyV-positive NSCLC cases is well worth doing.

\section{REFERENCES}

Hashida Y, Imajoh M, Nemoto Y, Kamioka M, Taniguchi A, Taguchi T, Kume M, Orihashi K, Daibata M (2013) Detection of Merkel cell polyomavirus with a tumour-specific signature in non-small cell lung cancer. $\mathrm{Br} J$ Cancer 108: 629-637.

Laude HC, Jonchère B, Maubec E, Carlotti A, Marinho E, Couturaud B, Peter M, Sastre-Garau X, Avril MF, Dupin N, Rozenberg F (2010) Distinct Merkel cell polyomavirus molecular features in tumour and non tumour specimens from patients with Merkel cell carcinoma. PLoS Pathog 6: e1001076.

Martel-Jantin C, Filippone C, Cassar O, Peter M, Tomasic G, Vielh P, Brière J, Petrella T, Aubriot-Lorton MH, Mortier L, Jouvion G, Sastre-Garau X, Robert C, Gessain A (2012) Genetic variability and integration of Merkel cell polyomavirus in Merkel cell carcinoma. Virology 426: 134-142.

Shuda M, Feng H, Moore PS, Chang Y (2013) Merkel cell polyomavirus and non-small cell lung cancer. Br J Cancer 108(12): 2623. 